\title{
Análisis histórico, territorial y constructivo de la fortaleza de Peñalcázar (Soria)
}

\author{
Historical, territorial and constructive analysis of the fortress of Peñalcá- \\ zar (Soria)
}

Ignacio Javier Gil Crespo*

\begin{abstract}
RESUMEN
La fortaleza de Peñalcázar, situada en el sureste de la provincia de Soria, formó parte tanto del sistema fortificado hispanomusulmán de la Marca Media como de las plazas-fuertes protagonistas de los enfrentamientos bajomedievales entre las coronas de Castilla y Aragón. El carácter de paso de este territorio, más que de frontera, explica las inquietudes y la preocupación histórica por su control. El artículo recopila todos los datos históricos dispersos sobre esta ciudad fortificada para elaborar un discurso que permite comprender su importancia histórica. La fortaleza tuvo un uso continuo desde su probable fundación califal hasta finales de la Edad Media y supuso un importante punto fuerte en la Raya en los momentos de la primera definición fronteriza. El estudio atento de ciertos abultamientos de evidente origen antrópico en la inmensa explanada sobre el otero que defiende naturalmente la villa y su relación con la trama urbana han permitido percibir unas estructuras ocultas que pueden corresponder con la antigua fortaleza hispanomusulmana. Los únicos restos conservados son parte de las murallas. El análisis comparativo y constructivo de estas fábricas con otros grupos constructivos revela que se trata de un tramo de muralla de factura cristiana con probable construcción entre los siglos XII y XIII, aunque con reparaciones tardías. Estos resultados revisan la datación comúnmente aceptada.
\end{abstract}

Palabras clave: Tapia de cal y canto, mampostería encofrada, fortificación, historia de la construcción

Peñalcázar fue una gran fortaleza cuya fundación parece remontarse a los últimos años del califato (ZAMORA LUCAS, 1961; LÁZARO CARRASCOSA, 2007). Durante los enfrentamientos fronterizos bajomedievales tuvo un protagonismo especial y en numerosas ocasiones aparece nombrada junto a las villas fortificadas de Serón de Nágima y Deza. Sin embargo,

\begin{abstract}
The fortress of Peñalcázar, placed in the Southeast of Soria, was part of the Muslim fortified system of the Marca Media and also was one of the fortified cities in the frontier of Castile and Aragon during the late medieval wars. The character of natural pass, rather than border, explains the historic worry for its control. The article collects all disperse historical data about this fortress to elaborate a discourse. Thus, the importance during all the Middle Ages is understood. This fortress was in use from its probable Muslim foundation since the finish of the Middle Ages. The fortress was an important point in the border in the moment of the first border definition. The study of several piles in the ground in the large plain over the hill that defenses the city and the relationship with the urban net have allowed to notice the hidden plan of the ancient Muslim fortress. The unique conserved rests are part of the city-walls. The comparative and constructive analysis amongst these masonries and other constructive groups reveals that its building was approximately in the 12th and 13th Centuries, but also late repaired. These results change the date commonly accepted.
\end{abstract}

Keywords: Formwork masonry, fortification, construction history

su alta capacidad defensiva -que fue alabada desde su primera reconquista por el Cid- perdió importancia desde la unificación de las coronas hispánicas bajo el común gobierno de los Reyes Católicos.

De la antigua ciudad fortificada de Peñalcázar no quedan hoy sino unas ruinas del despo-

* Dr. Arquitecto. Escuela Técnica Superior de Arquitectura de Madrid. Universidad Politécnica de Madrid 
blado y algunos lienzos de murallas. Tanto el tramo de muralla perimetral como el muro que algunos autores identifican como un lado de una antigua torre (LORENZO CELORRIO, 2003: p. 165), están construidos con fábrica de mampostería encofrada en la que se conservan algunas agujas e improntas constructivas que permiten su estudio detallado a nivel constructivo. De esta atribuida torre vigía musulmana de planta rectangular sólo se conserva el muro occidental y el arranque del orientado al norte. El muro oeste ha sido reaprovechado para albergar un lagar. La torre se ubica en la parte que vigila el valle del río Peñalcázar que une esta población con la de Almazul.

En Peñalcázar también hay restos de las murallas en el extremo nororiental de la población, en las que se conserva el hueco del ingreso, pero no el arco ni las jambas ni ningún elemento arquitectónico de la entrada a la población amurallada. Hay otra posible puerta con restos de cubo cilíndrico hacia la mitad del lienzo sur.

Las diferencias constructivas entre las fábricas de las murallas revelan varias fases en su construcción y su mantenimiento como plaza fuerte a lo largo de la Edad Media, revelado también por su estudio documental.

La técnica constructiva predominante en los muros de Peñalcázar es la tapia de cal y canto o mampostería encofrada y a través de la lectura atenta de sus paramentos se pueden estudiar sus fundamentos constructivos.

Este artículo ofrece un estudio monográfico sobre los restos arquitectónicos conservados de la fortaleza. Con el fin de comprender la dimensión territorial de la fortaleza se realiza un análisis del medio físico, así como se expone la permanencia de la población fortificada durante toda la Edad Media reconstruyendo un discurso histórico a través de noticias diseminadas. Por último, y tras enunciar una hipótesis sobre la situación y trazado de la posible fortaleza hispanomusulmana, se describen detalladamente desde un punto de vista constructivo y arquitectónico los lienzos de murallas y la torre conservados. Este texto supone una primera aproximación al conocimiento de la fortaleza previo a un anhelado estudio arqueológico ${ }^{1}$.

\section{ESTADO DE LA CUESTIÓN}

La plaza fortificada de Peñalcázar, que aparece en las crónicas y los documentos coetáneos nombrada sólo como Alcázar -Alcaçar, Alcoçer, Penna Alcaçar...- junto con las de Deza y Serón de Nágima y que fue conquistada por el Cid, sufre del olvido bibliográfico. La documentación sobre esta villa amurallada es bastante reducida. Zamora Lucas (1961: pp. 259-268) menciona algunas noticias del siglo X. Esta misma mención de la fortaleza aparece en otras publicaciones sobre la organización territorial andalusí de esta zona (CODERA, 1917: pp. 209-222; SERRANO-PIEDECASAS FERNÁNDEZ, 2007: pp. 277-300). En el Corpus de los castillos medievales de Castilla (ESPINOSA DE LOS MONTEROS Y MARTÍN-ARTAJO SARACHO, 1974: p. 451) no ofrece más que una vaga descripción del entorno en que se asienta y nombra algunos restos y objetos arqueológicos encontrados en su interior.

Entre las diversas obras generales o compendios sobre los castillos de la provincia de Soria, tan sólo el completo estudio de Lorenzo Celorrio (2003: pp. 163-165) le dedica unas páginas. En ellas describe los elementos defensivos conservados y da algunos detalles constructivos de los muros en base a los cuales aventura su datación.

Es la página web castillosdesoria.com, elaborada y mantenida por Jaime Fernández de Sosa, la que más información histórica, que no constructiva, ofrece. Aparentemente, dado que no cita directamente las fuentes de las que se nutre, está documentado sobre las

\footnotetext{
1 Este artículo se desprende de la tesis doctoral del autor titulada Fundamentos constructivos de las fortificaciones fronterizas entre las coronas de Castilla y Aragón de los siglos XII al XV en la actual provincia de Soria, dirigida por los profesores Santiago Huerta Fernández y Luis Maldonado Ramos. La tesis fue leída en la Escuela Técnica Superior de Arquitectura de Madrid en noviembre de 2013 y calificada con sobresaliente cum laude.
} 
referencias históricas extraídas de la obra de Pérez Rioja (1985: T. 1, pp. 234, 237; T. 2, pp. 30-31), como se verá a continuación. Por su parte, Cobos Guerra y Castro Fernández (1998: p. 58) tan sólo citan que junto a los castillos de Ciria y Cihuela formaba parte de la defensa de la frontera entre los siglos XII y XV.

Es a través de fuentes secundarias como se encuentran algunas descripciones, como el Nomenclátor... (BLASCO, 1909). Las crónicas de los reyes de Castilla mencionan en diversas ocasiones la villa y su fortaleza ya que fue escenario de batallas, tomas y devoluciones tanto durante la Guerra de los Dos Pedros (1356-1369) como durante el enfrentamiento con Navarra y Aragón a mediados del siglo $\mathrm{XV}$. No obstante este protagonismo, la villa y su fortaleza -la cual se describe siempre con adjetivos como «fuerte» $y$ «grande»- permanece olvidada en los principales textos de castellología, en parte debido a la ruina y desaparición de la fortaleza, hasta el punto de obviarla y dudar de su emplazamiento.

A pesar del periodo de calma que vivió la villa fortificada desde el final de la Edad Media, volvió a ser escenario de enfrentamientos a principios del siglo XVIII con la Guerra de la Sucesión. Este episodio lo narra Rabal (1889: pp. LXXX-LXXXI).

\section{ANÁLISIS TERRITORIAL}

La ciudad fortificada de Peñalcázar se encuentra hoy fuera de las rutas principales, ya que la actual carretera N-234 que comunica Soria con Calatayud transita desplazada más al norte que la ruta histórica. Sin embargo, hay numerosos relatos en las crónicas medievales en los que se comenta que tras atravesar desde Aragón la Raya o frontera se pasa por Peñalcázar, y eso explica su papel importante durante los enfrentamientos fronterizos entre Castilla y Aragón. La antigua vía de comunicación entre tierras aragonesas y castellanas debía entrar, por lo tanto, por el valle del río Henar, que se encuentra protegido por el castillo roquero de Cihuela por la parte castellana y por el de Embid de Ariza por la aragonesa. Al llegar a la villa amurallada de Deza, de la que hay constancia de la existencia de un castillo o casa fuerte, en lugar de remontar el curso del río hacia Gómara -cabeza importante durante los últimos años del califato, pero que pierde repercusión tras la reconquistase asciende la sierra de Deza por la ermita de San Roque para continuar por los páramos que circundan la sierra de Peñalcázar hasta La Alameda. Desde la ermita de San Roque de Deza hay comunicación visual directa con el castillo de Cihuela. Este hecho es un posible indicativo de la posible existencia de una torre vigía que pudo ser reaprovechada más tarde como ermita.

La villa de Peñalcázar se sitúa sobre una extensa muela calcárea de superficie plana y altos cantiles excepto por su extremo occidental, donde la ladera cae suavemente. En este punto es donde se ubicaba la entrada y aquí se conservan los restos fortificados.

La muela forma parte de los pliegues provocados por una de las fallas longitudinales que configuran el terreno de estas sierras ibéricas orientales: las sierras de Deza, Costanazo, Bigornia, Corija y Miñana. Por los corredores abiertos entre ellas, por los que discurre la red fluvial que los ha erosionado, se realiza la comunicación natural entre la fosa de Ariza y el valle del Jalón con los Campos de Gómara.

Peñalcázar tiene relación con la villa amurallada de Deza, si bien la comunicación visual directa se tiene desde Almazul, La Alameda, La Quiñonería, Carabantes y Sauquillo de Alcázar. La altura relativa de esta muela respecto a las sierras bajas alineadas que la rodean y el hecho de estar circundada por corredores por los que discurren el río Peñalcázar y el arroyo del Collado Hondo entre suaves pliegues del terreno, así como su forma de apéndice o proa, la dotan de unas cualidades poliorcéticas inigualables.

Al contrario que otros casos donde la ubicación del castillo corresponde claramente con el valle que sirve de comunicación, la situación de Peñalcázar responde más a las magníficas cualidades de su emplazamiento 
natural y a servir de puente entre dos de las principales vías: los valles del Manubles y del Henar (Fig. 1). En cualquier caso, los corredores de las sierras entre los pliegues característicos de este terreno formaban los accesos naturales al valle del Jalón. Como señala Carrión

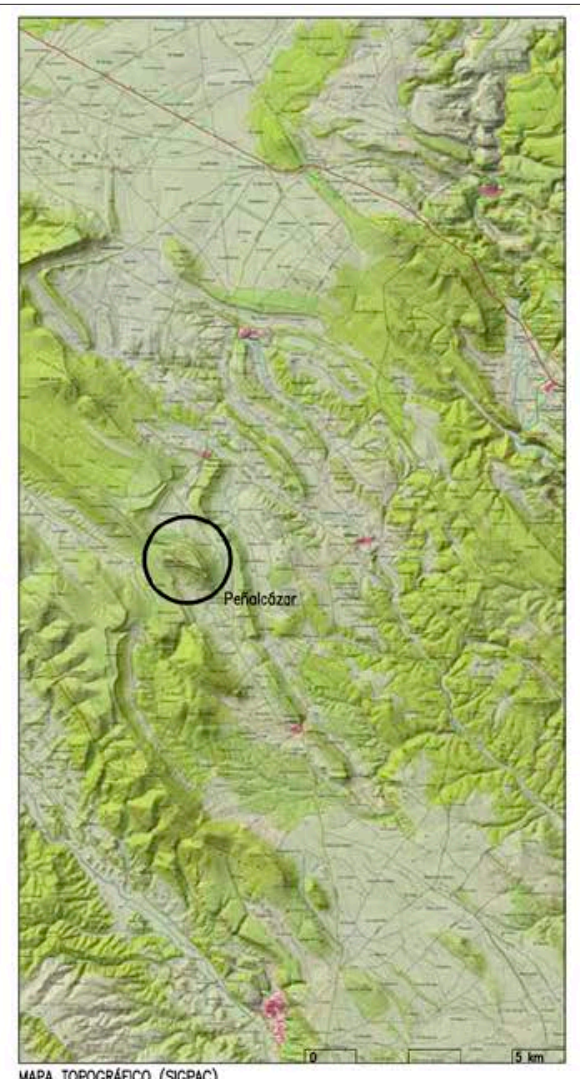

MAPA TOPOGRAFCO (SIGPAC)

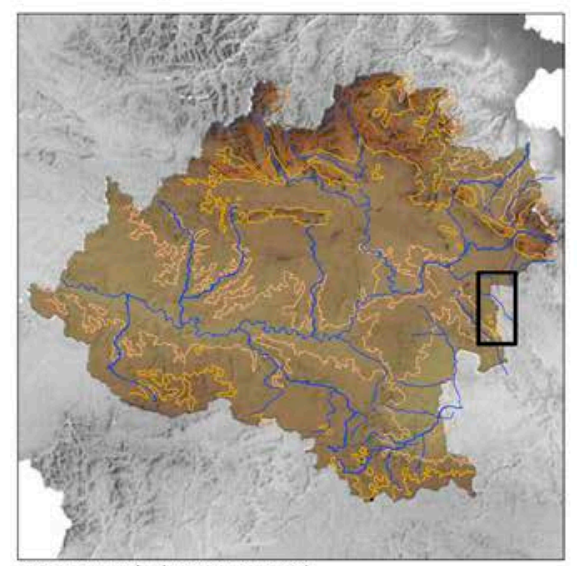

IAPA DE SITUAOON (PROUNCIA DE SORA)
VALLE DE LOS FIOS MANUBLES Y CARBBAN

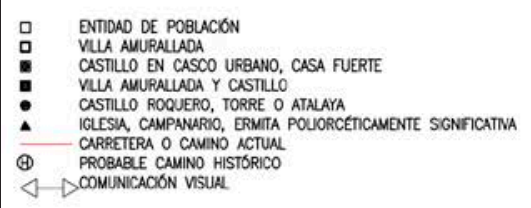

UStas de la fortaleza de perraccazar desoe El entorno
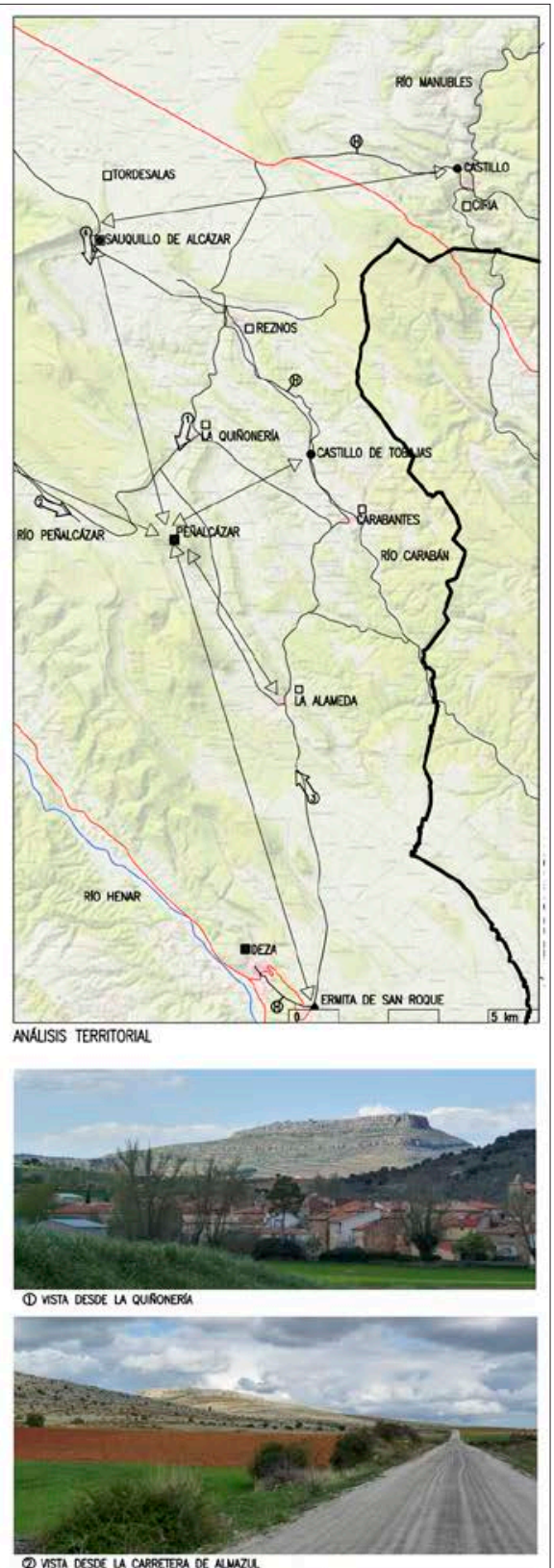

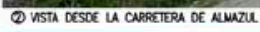

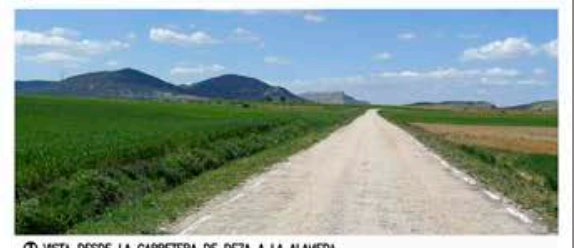

OT USTA OESOE UA CAREEER DE DEZA A LA NUVECA

Figura 1. Análisis territorial de los valles de los ríos Manubles y Carabán en torno a la fortaleza de Peñalcázar 
Matamoros (1998: pp. 95-96), uno de estos accesos lo constituye el trazado del río Carabán. Esta antigua ruta estaba controlada por la fortaleza de Peñalcázar y sus dependientes como Sauquillo de Alcázar o Carabantes que completan su dominio visual.

El desplazamiento de las vías principales de comunicación hacia los valles del Manubles y del Henar y el fin de los hostigamientos fronterizos, a finales de la Edad Media, colaboraron a que la villa fortificada de Peñalcázar perdiese su carácter de nodo para quedar en segunda línea y, a pesar de los hechos acaecidos durante la Guerra de Sucesión, a llegar irreversiblemente a la despoblación y el olvido.

\section{ELEMENTOS HISTÓRICOS}

La Peña de Alcázar formaba, junto con Ágreda, Almenar, Almazán, Berlanga, Gormaz, Medinaceli, San Esteban y Osma, el conjunto de plazas fuertes musulmanas para el control territorial de la cabeza del Duero y su valle y la divisoria entre éste y el del Ebro (RABAL, 1889: pp. XXVII-XVIII).

Los datos históricos conocidos relativos a esta fortificación son escasos. En el siglo X era una plaza bajo el dominio del valí del Campo de Gómara y el Jalón Medio, Amril Ben-Timlet -'Amrìl ibn Tīmlït-, de origen beréber y muerto en 972 y «cuyo nombre se conserva en el arroyo de Torambil-o de la Torre de Amril- que baja a juntarse con el Araviana. Sus hijos, cuyos nombres no son conocidos, gobiernan la torre paterna y Noviercas, Peñalcázar, Ateca, Deza y Ribarroya» (PÉREZ RIOJA, 1985: T. 1, p. 234). A la muerte del gobernador, se repartieron cinco fortalezas entre sus hijos que, según Zamora Lucas (1961: pp. 267-268), fueron Deza y Ateca -con toda probabilidad, según Zamora-, Buberos, Peñalcázar y Villarroya. Este episodio está narrado en el informe de Codera (1887, 187-193), recopilado en su Estudios críticos de Historia árabe espa- ñola (CODERA, 1917: 209-222) y recogido también por Manzano Moreno (1989: p. 285) y SerranoPiedecasas Fernández (2007: 277-300). Manzano sugiere que Budiel puede ser Pozuel de Ariza y al-Sujayra es probablemente Peñalcázar.

Los sistemas serranos situados en la margen exterior de la curva del Duero -sierras del Madero, de la Pica o del Costanazo- en torno a las cuencas del Rituerto y Araviana y el Campo de Gómara alojan un significativo número de torres que han merecido la atención de diversas investigaciones (GAYA NUÑO, 1932; DOMÍNGUEZ HERNÁNDEZ, 1984; 1984-85; LORENZO CELORRIO, 1994; BERNAD REMÓN, 1997; JIMÉNEZ ESTEBAN, 1997; COBOS GUERRA Y CASTRO FERNÁNDEZ, 1998; RETUERCEVELASCO Y COBOS GUERRA, 2002; LORENZO CELORRIO, 2003; LÁZARO CARRASCOSA, 2007; SERRANO-PIEDECASAS FERNÁNDEZ, 2007). Estas torres campesinas -así las denomina Serrano-Piedecasa (2007: p. 286) - se diferencian de las atalayas-vigías en que, aun habiendo conexión visual directa entre ellas, no jalonan vías de comunicación ni se sitúan en lugares altos de gran dominio visual. Estas torres están situadas en los llanos y se relacionan directamente con entidades de población a las que otorgan protección.

Las características formales y constructivas son su planta preferentemente cuadrangular o rectangular y el perfil sensiblemente troncopiramidal. Están construidas con tapia de cal y canto o mampostería encofrada -a juzgar por los agujales aún visibles en sus fábricas-y por huecos no tienen más que la entrada en altura y algunas aspilleras.

El territorio fronterizo entre el avance de Castilla y el retroceso califal no dejó de estar poblado por comunidades beréberes de los Banū Madā de la tribu Mașmūda (MANZANO MORENO, 1989: p. 285-291, RETUERCE VELASCO Y COBOS GUERRA, 2002; SARR, 2013), cristianas o musulmanes que necesitaron de un sistema fortificado para su protección y la de sus cosechas ante las continuas aceifas y razias ${ }^{2}$.

2 Manzano Moreno (2008, pp. 65-74) reflexiona sobre el desmoronamiento de la estructura territorial ocurrida en el valle del Duero por su condición fronteriza, ponderando la tesis de Sánchez Albornoz de que esta franja territorial se despobló conscientemente por los reyes astures contrariamente a otras tesis como la de Menéndez Pidal. El autor lamenta la ausencia de nuevas investigaciones y la pérdida de ocasiones que se ha tenido para sacar a la luz restos arqueológicos que la rapidez en terminar determinadas infraestructuras tal vez haya destruido. 
Existe un debate sobre si estas torres forman parte de un sistema califal de organización territorial dependientes de un ḥișn (castillo) -modelo que aún en el siglo X sigue en vigor en los territorios fronterizos (MANZANO MORENO, 2006: pp. 433-434)- o si por el contrario se trata de torres de presura de comunidades mozárabes levantadas tras el abandono de Ágreda tras su reconquista y la inclusión del territorio en los alfoces de las comunidades de villa y tierra nacidas tras la reconquista en el siglo XII (BERNAD REMÓN, 1997: p. 1158, COBOS GUERRA Y CASTRO FERNÁNDEZ, 1998: p. 45). Serrano-Piedecasas (2007: pp. 299-300) ofrece una interpretación que intenta aclarar este confuso panorama y explica la organización poblacional del territorio, en el que cada aldea o alquería tagarina o fronteriza tenía su torre refugio de ganado y producción agraria y dependía de un castillo o fortaleza con función fiscal y militar. Entre estas cabezas administrativas se encuentra Peñalcázar:

En este territorio, en la retaguardia de la frontera disputada de San Esteban, se ordenó un espacio de cultivo entre la sierra del Madero al norte, la del Moncayo al este y el Duero al oeste, que se constituyó focalizado hacia el sur, poblado en parte por musulmanes, posiblemente radicados alli desde la conquista en las tierras quinteadas, y por quinteros cristianos sometidos; dominados por una familia beréber mediante una red de explotaciones agrarias, de posesiones, nucleadas en torno a torres granero/rediles, que recogían el excedente destinado a sus señores territoriales, ubicados en Peñalcázar, Deza, etcétera, a donde eran transportados los frutos de la renta agraria que percibieron los Banu Amril ... La orientación estratégica hacia el sur es evidente, focalizándose en Peñalcázar el control visual de toda la red de torres campesinas.

La fortaleza de Peñalcázar formaba, por lo tanto, parte de la estructura territorial del cali- fato y los últimos años de dominación islámica sobre el oriente soriano. De ella dependerían diversos husun rurales, en expresión de Acién Almansa que son estas torres refugio y que, a excepción de las zonas fronterizas, desaparecerán con la instauración del control territorial califal en al-Ándalus (MANZANO MORENO, 2006: pp. 433 Y SS:; ACIÉN ALMANSA, 2008: p. 151-152).

La plaza de Peña Alcázar o Peñalcázar, como es nombrada más recientemente ${ }^{3}$, vuelve a ser citada en el siglo XI cuando el Cid la asedia y conquista -era todavía territorio de dominio islámico- para después venderla a los musulmanes del Jalón (PÉREZ RIOJA, 1985: T. 1, p. 237). En el Cantar aparece nombrado como Alcoçer y se refiere a él como una gran fortaleza:

\section{Y sobre Alcoçer mio Çid iba posar,}

En un otero redondo, fuerte y grande;

\section{Quando vio mio Çid que Alcoçer no sele daba, \\ En este castiello grande haber habemos preso,}

\section{Vino posar sobre Alcoçer, en un tan fuerte logar, \\ Sacolos a çelada, el castiello ganado ha.}

La importancia relativa de Peñalcázar no decrece durante la siguiente etapa de gobierno realengo castellano, sino que de ser una posible cabeza administrativa de un territorio de importancia circunstancial -como sugiere Manzano Moreno (1989: p. 291): «su práctica ausencia de las fuentes escritas mueve a pensar que a todos los efectos debía de tratarse de un territorio de importancia marginal»-se convierte durante la Baja Edad Media en una de las fortalezas protagonistas de las diversas guerras y litigios fronterizos entre Castilla y Aragón.

Es reconquistada a principios del siglo XII por Alfonso I el Batallador de Aragón cuando

\footnotetext{
3 Tanto Miñano (1826-1829) como Madoz (1845-1850) y Blasco (1909) transcriben el topónimo de la villa como Peña Alcázar. No es hasta época reciente cuando se produce la contracción entre ambos términos al coincidir las vocales final y primera de cada uno.
} 
se hace con todo el territorio que hoy forma el oriente soriano. Se encuentra entre las fortalezas que fueron devastadas $y$, a este respecto, escribe Zamora Lucas (1961: p. 268):

\begin{abstract}
A finales del siglo XII, el papa Alejandro III, apremiaba porsu bula, dada en Preheste, a los Obispos de Ávila y Sigüenza para que restituyesen al de Tarazona los derechos que le correspondian en compensación de la Villa de Soria, y cita expresamente Turrem Ambrel, Boroviam, et Achacher o Alcacer (que debe ser Alcázar, Peñalcázar) que le devastaron y aun destruyeron sus iglesias.
\end{abstract}

Con el avance de la Reconquista y el desplazamiento del frente allende el Tajo, este territorio sostiene un período de relativa paz en el que procede a organizarse políticamente y jurisdiccionalmente. Se estabilizan y se organizan los núcleos urbanos al amparo de los Fueros y se organizan en torno al concejo de la ciudad de Soria donde se administra el poder (MONSALVO ANTÓN, 2003; MALALANA UREÑA, 2009). Junto a Borobia y Tordeambril, Peñalcázar queda anexionada a la Tierra de Soria como puesto fronterizo bajo el mando de los caballeros sorianos (DIAGO HERNANDO, 1992: pp. 358-359), si bien hacia 1296 ya se había separado de dicha jurisdicción (DIAGO HERNANDO, 2005: p. 57). El infante Alfonso de la Cerda albergaba ambiciones sobre Castilla y en 1304 tiene un pleito por el que debe entregar a Fernando IV las villas de Almazán, Serón, Deza y [Peña] Alcázar en el plazo de un año (MASIÁ DE ROS, 1994: pp. 122-123):

Dos días después de esta sentencia, el 10 de agosto, el rey Fernando promete que si los lugares cedidos a Alfonso de la Cerda no alcanzan a producir una renta anual de cuatrocientos mil maravedises, le aumentará las donaciones hasta alcanzar dicho límite. Coincidimos con el parecer expresado por Zurita, acerca del cuidado que se tuvo al elegir las villas que se dieron al infante Alfonso, buscando que en lugar de formar un todo compacto, estuviesen repartidas por toda la geografía castellana, gallega, y andaluza, lejos de la fron- tera con Aragón. Así se vería obligado a devolver Serón, Almazán, Alcázary Deza, y Jaime II, promete solemnemente a Fernando IV, no prestar ayuda al infante Alfonso en el caso de que éste quiera retener dichos lugares, o no cumplir cualquiera de los extremos de la sentencia arbitral.

Durante la guerra de los Dos Pedros, Peñalcázar tiene un papel relevante junto con otras fortalezas cercanas. En las primeras escaramuzas de esta guerra intestina entre hermanos, don Enrique conde de Trastámara trata de hacerse con la villa tras pasar la Raya en 1357, pero ha de retroceder a Aragón ante el socorro del monarca castellano. Este episodio está narrado en las diversas crónicas. En la Descripción histórica del Obispado de Osma (LOPERRÁEZ CORVALÁN, 1788: T. 1, p. 301) se lee que el Conde de Trastámara, don Enrique: «entró por tierra de Soria, y tomó por combate á la villa de Seron: de allí pasó á un lugar inmediato que llaman Alcázar, del que no se pudo apoderar por tener un castillo muy fuerte».

Su importancia durante la guerra entre las Coronas aparece ligada a la de Serón, Monteagudo y Deza. En la Crónica de Pedro I (LÓPEZ DE AYALA, 1779: p. 494; TAMBIÉN CITADO POR MARTíNEZ ALONSO, 2012: p. 109) se lee que en 1358:

\section{el Conde Don Enrique era entrado en Castilla por tierras de Serón ... é que el dicho Conde llegara a la villa de Serón, e la robara: é como dende fuera á un lugar é castillo fuerte que dicen Alcazar, que es de Soria, é que le combatió, cuidandole tomar, para poner y gentes para facer de alli guerra; pero non lo pudiera tomar; é que se tornára á Aragon.}

La paz de Terrer de mayo de 1361 supuso para Castilla la devolución de las plazas y castillos ocupados en Aragón, en especial aquéllos situados cerca de la frontera. A cambio, Aragón se comprometió a que los rehenes castellanos y los caballeros que se pasaron al bando aragonés volviesen a Castilla. Entre estos castillos que retornan a poder castellano se encuentra la fortaleza de Peñalcázar, señalada en los textos como Alcázar: 
Los rehenes personales fueron por Castilla Fernando de Castro y Martín Gil de Alburquerque. Por Aragón el conde de Osona y Pedro de Luna. Los castillos entregados por el mismo concepto, fueron por Castilla Deza, Alcázar y Cigüela. Por Aragón, Ariza, Alhama y Verdejo. Todos ellos debían ser puestos en poder del cardenal legado para que pusiese en ellos alcaydes, que no podian ser ni castellanos ni aragoneses (MASIÁ DE ROS, 1994: p. 284).

En 1434, el castillo es donado a Beltrán de la Cueva. Poco tiempo más tarde, en 1445 las fortalezas de Atienza y Peñalcázar se vuelven el escenario de los enfrentamientos entre el infante don Juan, rey de Navarra posteriormente, y don Juan de Luna. En 1445, Juan II, poco antes de la batalla de Olmedo, separa de la jurisdicción de la ciudad de Soria, entre otras villas y lugares, la villa y fortaleza de Magaña y se la concede como merced a su guardamayor Juan de Luna (DIAGO HERNANDO, 1991: p. 70). El 3 de marzo de 1446 don Juan de Luna, sobrino de don Álvaro y heredero de sus señoríos, es nombrado capitán mayor de la frontera de Aragón. En 1447, Juan de Barrionuevo, «alcaide de la fortaleza de Peñalcázar por el concejo de Soria, no pudo evitar que los partidarios del rey de Navarra se hiciesen con el control de la citada fortaleza, desde la que en adelante sembrarían la violencia en Tierra de Soria para infortunio de los campesinos residentes en las aldeas próximas a la frontera». Para recuperarla, Juan II envió sus huestes a Soria ese mismo año, aunque no es hasta algunos años más tarde cuando Enrique IV devuelve la fortaleza aragonesa de Verdejo a cambio de la de Peñalcázar (BLASCO, 1909: p. 405; PÉREZ RIOJA, 1985: T. 2, pp. 30-31; DIAGO HERNANDO, 1991: pp. 69 Y 76-77) ${ }^{4}$.

En 1459-60 el concejo de Soria designa a su regidor, Juan Torres, para que solicitase a la reina la devolución del castillo de Magaña que estaba en manos de Juan de Luna. Juan Torres era señor de Almenar y alcaide de Peñalcázar (DIAGO HERNANDO, 1991: p. 79).
Peñalcázar perteneció a las tierras de jurisdicción realenga, aunque por su posición fronteriza, sus tenentes gozaban de cierta independencia, lo que llevó a una señorialización no oficial de esta tierra. La familia Torres fue la depositaria del derecho de tenencia y gobierno de la villa fortificada y sus aldeas de La Quiñonería, La Alameda y Carabantes a finales de la Edad Media (QUINTANILLA RASO, 1986: p. 887; DIAGO HERNANDO, 1988: pp. 23-43).

Peñalcázar fue de las tierras realengas que no sufrió enajenación ni vio trastocado su régimen jurídico, ya que siempre gozó de cierta independencia por su importante labor defensiva de la frontera. Diago Hernando (1987: p. 204) menciona un documento de 1484 en el que se enumeran los lugares segregados del realengo de la Tierra de Soria para ser convertidos en señoríos: Magaña, Ciria y Borobia, Hinojosa de la Sierra, Tejado, Almenar, Castil de Tierra, Nomparedes, Bliecos y Pinilla: «el documento incluye en la relación a la Penna de Alcaçar, la actual Peñalcázar, fortaleza defensiva de la tierra de Soria frente a Aragón, y que como tal, junto con sus aldeas de Caravantes, La Quiñorenía y La Alameda, gozaba de un estatuto especial, sin estar transferida al señorío de ningún noble». La villa de Peñalcázar estaba eximida del pago de impuestos por su labor de vigilancia y defensa de la frontera y su poder lo ejercitaba el tenente designado, que sin ser propiamente un señorío, en la práctica actuaba como tal ya que había cierta relación de vasallaje con respecto a los vecinos de las aldeas del término además de por la sucesión hereditaria de los Torres en la tenencia de la fortaleza a finales de la Edad Media (DIAGO HERNANDO, 1987: p. 204 Y 217).

El último episodio bélico que soportó la fortaleza fue el saqueo durante el avance del archiduque en 1706 durante la Guerra de la Sucesión. Rabal (1889: pp. LXXX-LXXXI) describe los hechos. Las tropas - «ocho mil hombres y diez piezas de artillería a las órdenes del conde de Sástago»-que buscaban apoderarse

\footnotetext{
4 Sobre la ocupación navarra de la fortaleza de Peñalcázar, queda registro, según Diago Hernando (1991: p. 83, nota 37) en el Archivo General de Simancas, leg. 84-1.
} 
de Burgos entraron por la frontera soriana. Precisamente la toma por capitulación de Peñalcázar supuso la necesidad de fortificar Soria y armar a la población «con chuzos y lanzas por falta de fusiles, y resueltos á resistir de cualquier modo» en noviembre de 1706.

La que fue una plaza importante en la época medieval se quedó reducida a una pequeña población de 70 casas en el siglo XIX (MADOZ, [1845-1850] 1993: p. 188), con una población de 148 almas a principios del XX (BLASCO, 1909: p. 406) y hoy se encuentra despoblada.

\section{RESTOS CONSERVADOS}

La villa fortificada de Peñalcázar se asienta sobre una extensa muela calcárea con escar- pes verticales en casi todo su perímetro. Sobre estos escarpes se elevaba una muralla -de la que se han mantenido muy pocos restos- que cerraba y protegía la población que se desarrollaba en su interior, hoy día un despoblado (Fig. 2).

De lo que debió ser una extensa muralla que posiblemente rodeaba gran parte de la muela, de unos $725 \mathrm{~m}$ de longitud por 300 de anchura en su punto de mayor dimensión -tiene una forma de lágrima con el ápice hacia el sureste- no quedan sino pocos restos aislados, principalmente en el flanco occidental y septentrional. Sin embargo, Lorenzo Celorrio (2003: p. 165) opina que no debió estar totalmente rodeada de murallas, como sí lo están otras villas amuralladas de asentamiento similar como es el caso de Rello, sino que se
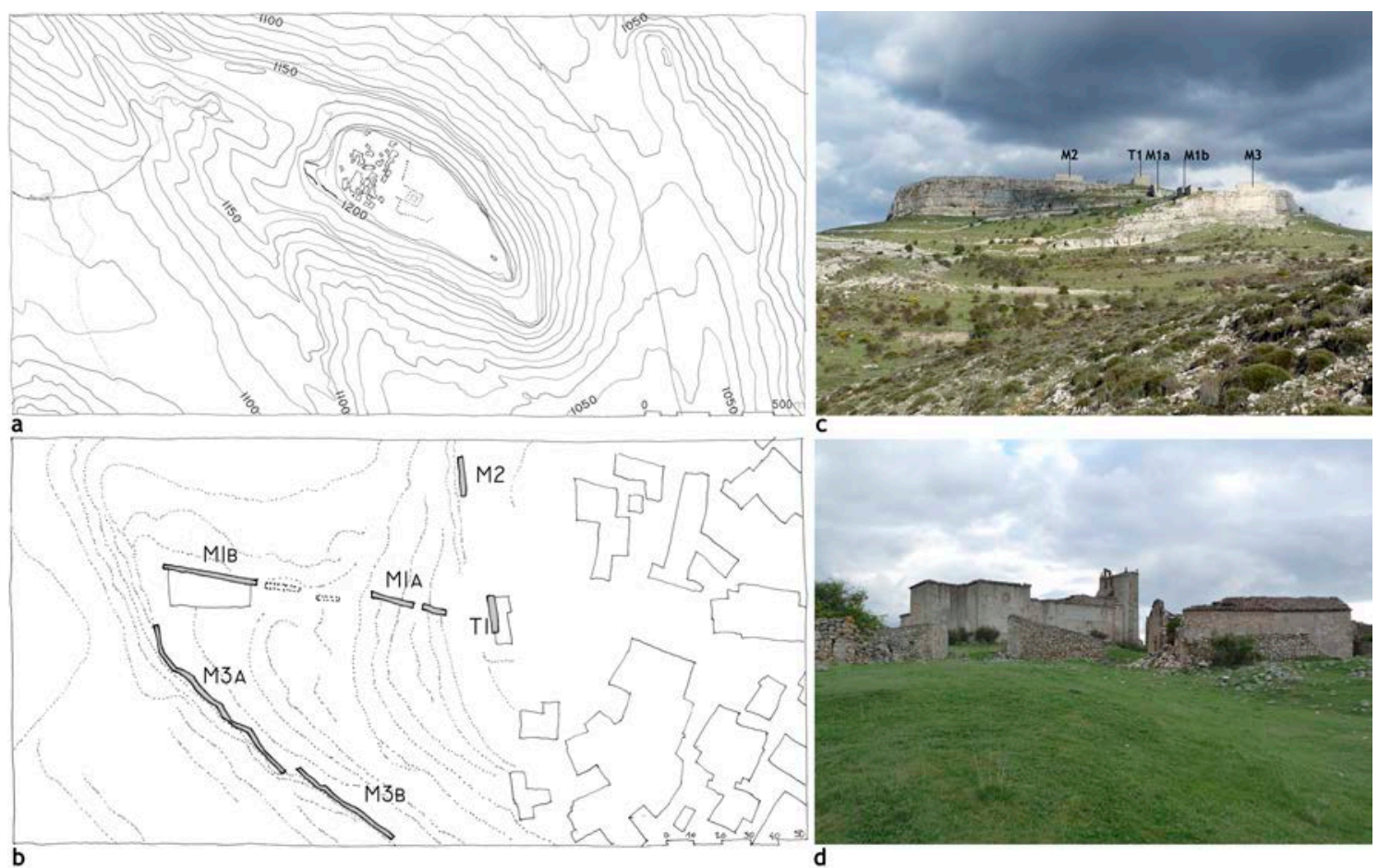

Figura 2. a. Mapa topográfico del entorno inmediato de la muela calcárea sobre la que se asienta la fortaleza y la población de Peñalcázar, en la que se ha señalado la posible ubicación de la fortaleza con líneas a trazos. $\boldsymbol{b}$. Planta de detalle de los restos conservados de las murallas de Peñalcázar. M1: muralla donde se sitúa el ingreso al recinto amurallado, de la que se conservan dos tramos; M2: tramo del lienzo noroccidental de la muralla; M3: lienzo suroccidental de la muralla perimetral, de la que se conservan aproximadamente $117 \mathrm{~m}$ de su trazado y que se encuentra divida en dos tramos por el hueco de un posible portillo; T1: muro occidental de una torre. c. Vista desde el noroeste con indicación de los restos amurallados conservados. $\boldsymbol{d}$. Diversos abultamientos del terreno alineados y perceptibles desde la ortofotografía señalan el amontonamiento de ruinas de procedencia antrópica que pueden corresponderse con las de la fortaleza. Vista de la explanada donde probablemente se ubicó el alcázary, al fondo, la iglesia y el caserío de la población. 
levantaron murallas en aquellos puntos donde el escarpe natural no ofrecía una defensa suficiente. Así, es en el extremo occidental donde se concentran los restos conservados, alrededor del camino de subida y entrada. El autor antes citado sitúa la fortaleza en este extremo en el que se conservan los escasos muros en pie. Sólo una exploración arqueológica de la ciudad permitiría saber qué tramos pudieron estar amurallados así como la extensión y dimensión máxima de la villa.

Sin embargo, al analizar la ortofotografía servida por el SIGPAC, se pueden apreciar las huellas de unas estructuras lineales al sureste de los restos de la población, en la parte central de la meseta. Resulta significativo que la orientación de esta estructura visible desde la ortofotografía - paralela al eje mayor de la mesa natural- es la misma que el caserío, entre el cual aparece girada la iglesia que mantiene su tradicional orientación hacia el oriente. No hay razón topográfica para que el caserío tenga una orientación distinta que la de la iglesia. Cabe la posibilidad de que estas huellas pertenezcan al antiguo alcázar o fortaleza. Las dimensiones que se pueden tomar desde este medio gráfico revelan que se trata de una estructura rectangular de unos $105 \times 75$ metros, desplazada unos $30 \mathrm{~m}$ de otra línea transversal a la muela de unos $95 \mathrm{~m}$ de longitud. Son unas dimensiones considerables si se tienen en cuenta las de otras fortificaciones cercanas. No obstante, las crónicas y los datos históricos de los que se dispone siempre hacen referencia a esta fortaleza como fuerte y grande.

Por último, sobre el extremo suroriental de la meseta, con forma de proa, se ubica la ermita de San Roque, que en vez de estar orientada hacia el este como es habitual en las construcciones religiosas cristianas, sigue la misma orientación que las huellas de la posible fortaleza. Es posible que esté asentada sobre alguna torre vigía que controlaba tan singular y estratégico punto de observación. Desde este punto se controlan los valles del arroyo del Collado Hondo y de los ríos Peñalcázar y Carabán, teniendo comunicación visual directa con La Alameda, Carabantes, Sauquillo de Alcázar y La Quiñonería.

\section{FUNDAMENTOS CONSTRUCTIVOS}

Se han seleccionado tres muros y los restos interpretados tradicionalmente como una torre para el análisis de la construcción de las murallas de Peñalcázar. El lienzo que cerraba el acceso desde el noroeste, ejecutado con dos caras de mampostería careada rellenas de cal y canto y cascotes en el primero de ellos. El segundo se encuentra en la parte más septentrional de la muela, paralelo al camino que sube a la puerta antes mencionada. Por último, el tercer muro a estudiar es un lienzo almenado que se alza sobre el cantil y del que se conserva algo menos de 120 metros de su trazado.

\section{Muro M1}

La muralla de la ciudad tiene varias fases constructivas. El tramo que cierra la rampa natural hacia la meseta superior de la muela se ha denominado como muro M1 (Fig. 3). La gruesa muralla $-2,40 \mathrm{~m}$ de espesor- en la que se abre el hueco de entrada septentrional conserva dos tramos de unos 34,40 metros el tramo más occidental y unos 28,70 el oriental, éste con una brecha que lo vuelve a partir en dos lienzos de unos 17 y 8,20 metros. Entre ellos se abría la puerta, de la que no quedan restos más que el hueco donde se alojaba una de las trancas de madera interiores. Se puede suponer, como ha sido habitual en otras ocasiones, que si la fábrica de este elemento estaba más trabajada que la mampostería de los lienzos, se ha podido reutilizar en las construcciones de la población. Blasco (1909: p. 405), que conoció la villa en 1840 y se lamenta 69 años después del proceso de despoblación que estaba ocurriendo en ese momento, habla de que la muralla se cerraba con una puerta de hierro, pero no se puede saber si era la puerta original ni sus características.

La construcción de los lienzos de esta muralla es de mampostería careada rellena de cascotes y es similar a la de otras murallas como las de Almazán o Ágreda. Las únicas improntas constructivas aparecen tras la primera capa de mampostería, que se ha desprendido accidentalmente o ha sido sustraída en las partes bajas del muro. Tras el paramen- 


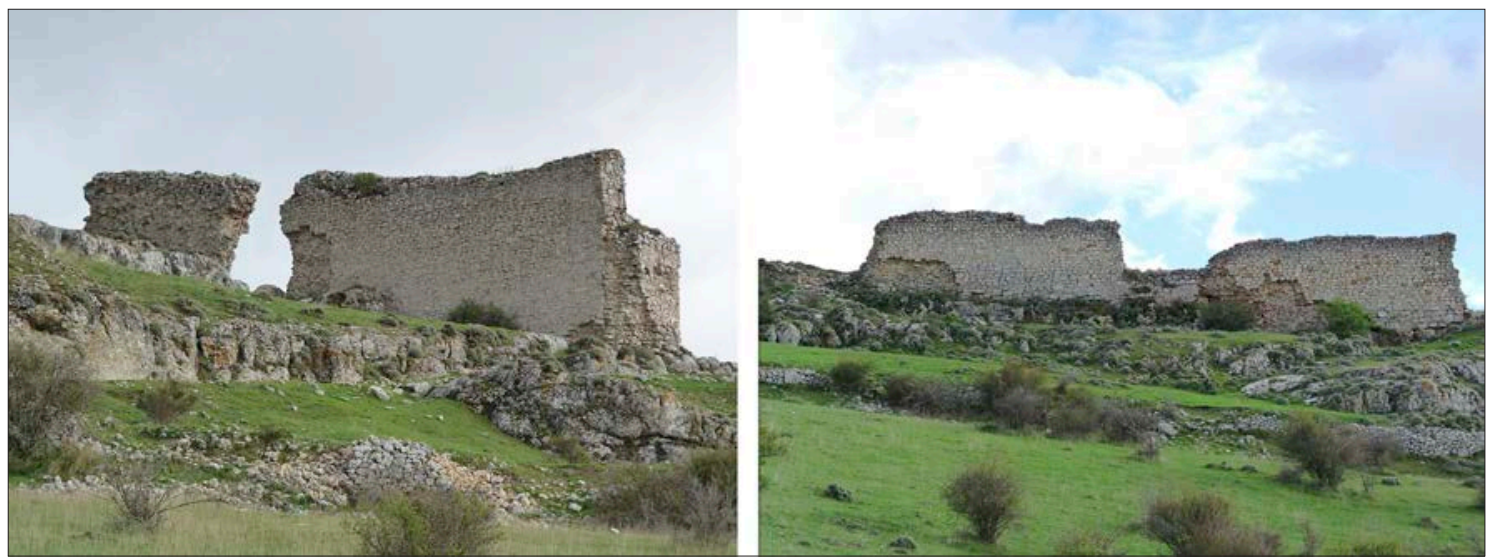

Figura 3. $\boldsymbol{a}$. Tramo Mla del lienzo noroccidental de las murallas de Peñalcázar. $\boldsymbol{b}$. Tramo M1b del lienzo noroccidental de las murallas de Peñalcázar.

to de mampostería se advierte una fábrica de cal y canto en la que se observa una serie de mechinales con una sección aproximada de $4,5 \times 4,5 \mathrm{~cm}$ y distribuidos cada $70-75 \mathrm{~cm}$. Estos mechinales no son pasantes y su profundidad alcanza los 95-100 cm. Es significativo que no tengan proyección en el exterior de la fábrica, si bien es posible que fueran taponados una vez retiradas las agujas.

Los agujales son apreciables en la parte inferior del muro, casi a ras del terreno (Fig. 4),

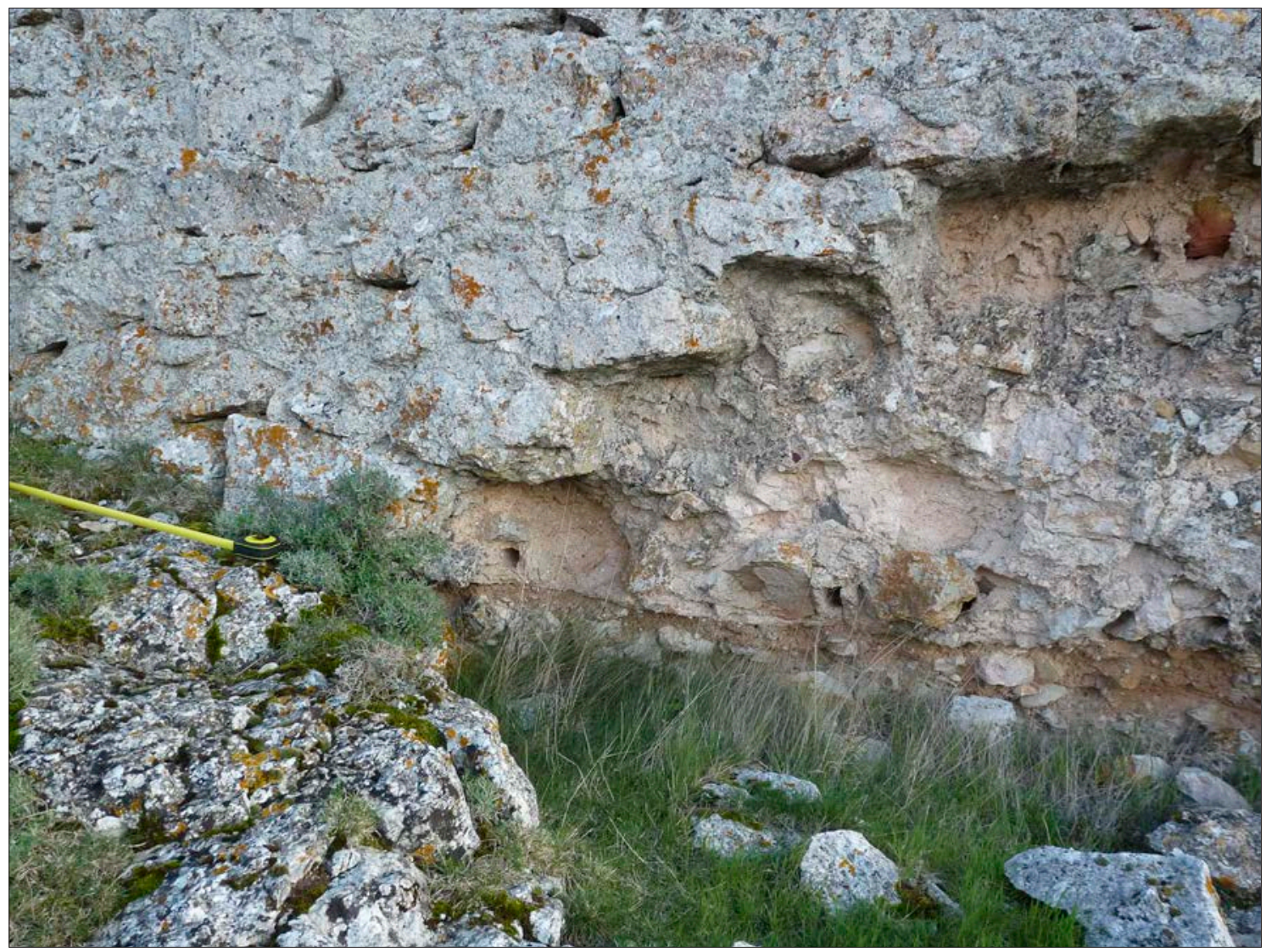

Figura 4. Detalle de la parte baja del muro M1a del lienzo noroccidental de las murallas de Peñalcázar donde se aprecian los mechinales de las agujas de la fábrica de tapia de cal y canto que rellena el espesor del muro. 
por lo que no se corresponden con las huellas de un posible andamiaje, además de ser pequeños para tal fin. No se aprecia desde el paramento exterior ningún resto de cuñas, espartos, cruces de San Andrés ni ningún dispositivo de arriostramiento. Sin embargo, el considerable espesor del muro -240 cm- parece excesivo para unas agujas de tan pequeña sección, por lo que no parece plausible que las agujas fuesen pasaderas. En el trabajo sobre las fortificaciones de cal y canto levantadas entre mediados del siglo XII y el primer tercio del XIII en la frontera entre los reinos de León y Castilla se incluye una sección de la disposición de los tapiales del muro de Almanza en León en el que se construyeron sus muros con medias agujas en la base ancladas con una cuña (COBOS GUERRA, CASTRO FERNÁNDEZ Y CANAL ARRIBAS, 2012: p. 108). Esta disposición constructiva puede formularse como hipotética para el muro M1 de las murallas de Peñalcázar a falta de catas en el muro que destapen otras improntas constructivas.

En el paramento de mampostería del muro apenas se aprecian los niveles constructivos y no hay ningún mechinal superficial. Además, la mampostería está careada para mantener la planeidad del paramento. Estos datos parecen indicar la ausencia de tapiales o encofrado y es posible que estas agujas pudieron emplearse como guías para sostener tendeles o unas tabicas que asegurasen la horizontalidad de los niveles y la verticalidad de los paramentos de mampostería entre los que se vertía el hormigón de relleno.

\section{Muro M2}

Se ha nombrado como muro M2 al tramo de muralla más septentrional del conjunto (Fig. 5). Casi alineado con el muro de la posible torre vigía hay un tramo de 16,80 m de longitud construido con mampostería y cal y canto encofrado en cuatro hilos constructivos -extramuros hay uno más que salva el desnivel- de unos 90-110 cm de altura y un espesor de $125 \mathrm{~cm}$. La fábrica conserva restos de las agujas de madera contenidas en los mechinales. Estas agujas, no pasaderas, tienen una sección cuadrangular de $10 \times 10 \mathrm{~cm}$. Se observan en la parte superior de la oquedad unas lajas dispuestas para evitar la adhesión de la aguja a la fábrica y poderla retirar después para reutilizarla. De ahí la homogeneidad en las dimensiones de las oquedades. En la parte superior del muro y visible gracias a su ruina se aprecia la huella de un puntal o codal inclinado que quedó embebido en el interior del muro.

La tapia se forma por cajones constructivos con junta vertical de una longitud que oscila entre los 280 y los $310 \mathrm{~cm}$. Estas juntas se aprecian a partir del tercer nivel. Del análisis del paramento se observa que el proceso de construcción se inició en el extremo norte y continuó hacia el sur, al menos en los niveles
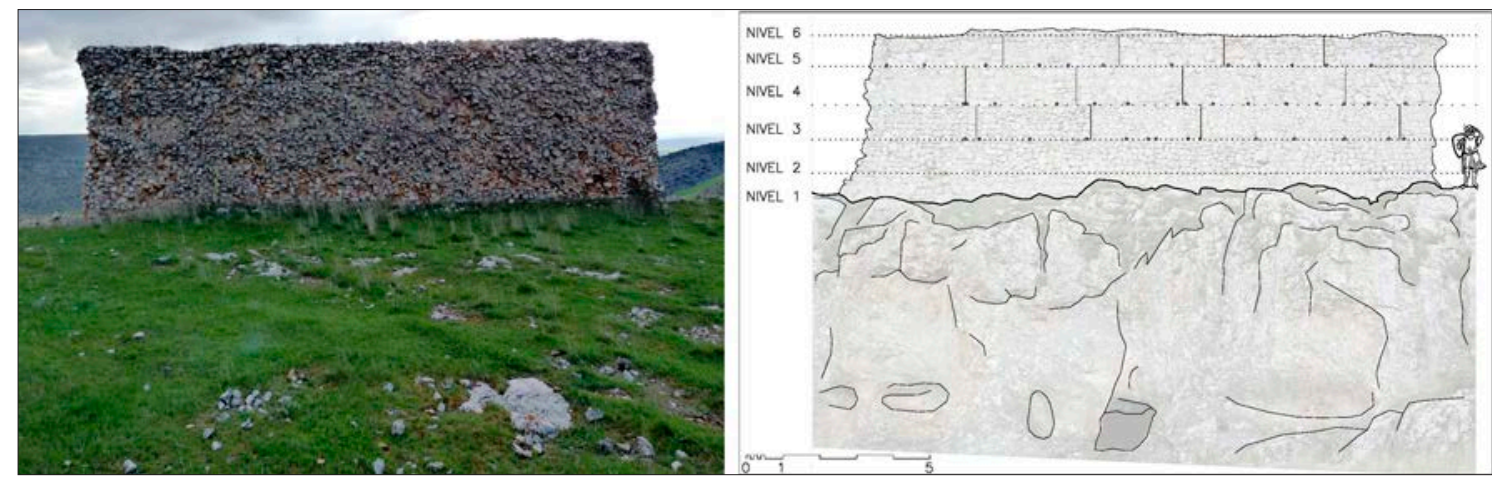

Figura 5. a. Vista intramuros del muro M2 de las murallas de Peñalcázar.

b. Alzado extramuros del muro M2 de las murallas de Peñalcázar, con indicación de los niveles constructivos y las juntas entre los sucesivos cajones de tapia de cal y canto, así como de los agujales visibles. La secuencia constructiva revela que la construcción procedió de norte (izquierda) a sur (derecha). 

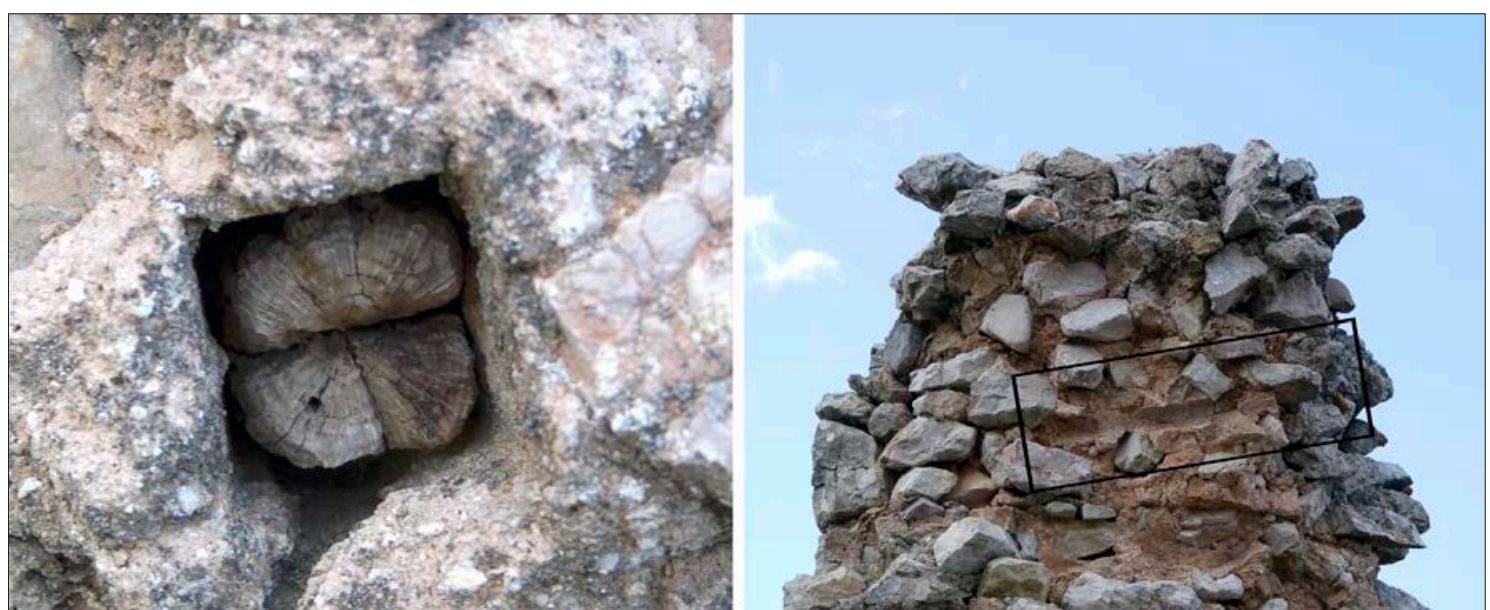

Figura 6. a. Detalle de una aguja de madera de sección cuadrangular conservada en el muro M2. b. Detalle de la cabeza del muro M2, en el que se advierte la huella inclinada de un codal o puntal interior.

tercero y cuarto. Cada tapial se soportaba por tres costales apoyados en sendas agujas, las cuales distan entre sí unos 90- $110 \mathrm{~cm}$.

En el corte meridional del muro se aprecia la marca de una pieza de madera que se introduce de manera inclinada en el grosor de la fábrica (Fig. 6). Aunque podría tratarse de un puntal interior de los tapiales, el rebajado ángulo de inclinación y el hecho de no arrancar desde el inicio del nivel constructivo podrían indicar que no se trata de un puntal provisional para evitar el vencimiento del interior de los tapiales sino que pudo ser un fragmento de madera de sección circular caído dentro de la masa de cal y canto cuando ésta se vertió para formar el muro. No se han observado más improntas de este tipo, por lo que no se puede aventurar si se trata de un puntal o no.

Así como la fábrica de mampostería del paramento extramuros guarda cierta planeidad merced a la labra superficial de los mampuestos, la cara interior del muro parece haber sido despojada de la capa externa de mampostería, sirviendo quizá como cantera que haya suministrado de piedra con algo de labra para las construcciones de la población intramuros cuando ya no hubo razón defensiva de mantener las murallas.

\section{Muro M3}

El muro asignado como M3 es el muro que se eleva sobre el cantil occidental y del que se conserva un lienzo de planta quebrada -se adapta al perímetro de la muela- de 117,5 metros de longitud. Esta muralla, con tramos almenados, presenta varios estados constructivos diferentes (Fig. 7).

El primer tramo, el más cercano al muro M1, se levanta con cinco hilos constructivos, correspondiendo el último al remate almenado, siendo la altura de los tapiales de unos 100-110 cm de altura. Se observan unos mechinales pasantes de perfil rectangular vertical de $8,5 \times 6$ y $14-15 \times 9 \mathrm{~cm}$ separados cada 130-140 cm. El espesor del muro en su primer tramo es de 115 a $130-150 \mathrm{~cm}$. Este tramo conserva 15 almenas alternativamente aspilleradas. El quinto nivel tiene menor grosor para formar un estrecho adarve y los mechinales se sitúan sobre este nivel del adarve. Es posible que estos mechinales, una vez cumplida su función auxiliar durante la construcción de las tapias de cal y canto, fuesen utilizados para sostener tanto una defensa vertical avanzada de madera como un cadalso como para formar una plataforma hacia intramuros sobre la que permitir la movilidad de los defensores y su maquinaria de defensa como, por ejemplo, algún trebuchet de pequeño tamaño. 


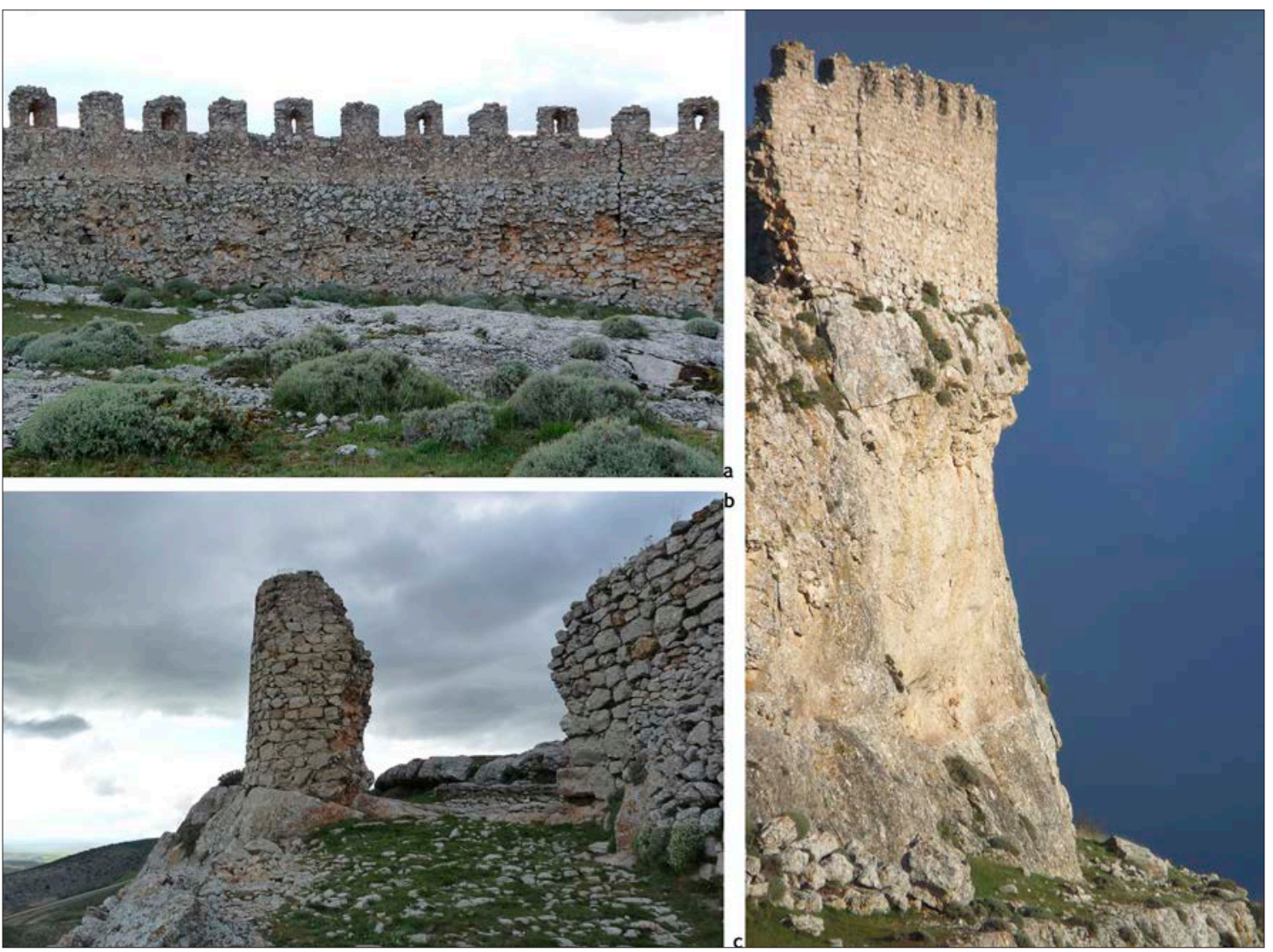

Figura 7.

a. Vista intramuros del muro M3 de las murallas de Peñalcázar. $\boldsymbol{b}$. Ubicación de la segunda puerta abierta en una cremallera del tramo meridional del muro M3 de las murallas de Peñalcázar. c. Vista extramuros del tramo septentrional del muro M3 de las murallas de Peñalcázar sobre el alto cantil formado por la costra calcárea que corona la muela sobre la que se asienta la ciudad.

En la parte media la construcción difiere, ya que los mechinales reducen su sección y no son pasaderos. En este caso se utilizaron agujas de 4,5 × 4,5 cm cada $65 \mathrm{~cm}$. Algunos de estos mechinales tienen una sección de sector de circunferencia correspondiente al empleo de agujas planas de rollizos aserrados (Fig. 8).

Por último, el tramo más meridional tiene unos mechinales de $14-15 \times 9 \mathrm{~cm}$ no pasantes de unos $50 \mathrm{~cm}$ de profundidad separados horizontalmente cada $155 \mathrm{~cm}$. Hay una junta constructiva a los lados de la cual se repiten los mechinales. El espesor del muro en esta parte es de $140 \mathrm{~cm}$. En este caso, los mechinales no son pasaderos, sino que se introducen en el muro unos dos pies o $60 \mathrm{~cm}$. Las escuadrías de las agujas son más pequeñas y, en algunos casos, éstas se han dejado perdidas dentro del muro. El paramento extramuros de esta fábrica es de mampostería, siendo encofrada sólo la parte intramuros.

\section{Torre T1}

El tramo que algunos autores identifican como un lado de una antigua torre hispanomusulmana (LORENZO CELORRIO, 2003: p. 165) -designada como T1-, es de fábrica de mampostería encofrada en la que además se conservan algunas agujas (Fig. 9). Se considera que este muro corresponde a una torre porque se conserva el arranque de los cuatro primeros niveles del muro septentrional que acomete con el lienzo principal, no habiendo además un posible encuentro trabado con el muro M2 que discurre más al norte: la esquina noroccidental de esta torre presenta unos paramentos 

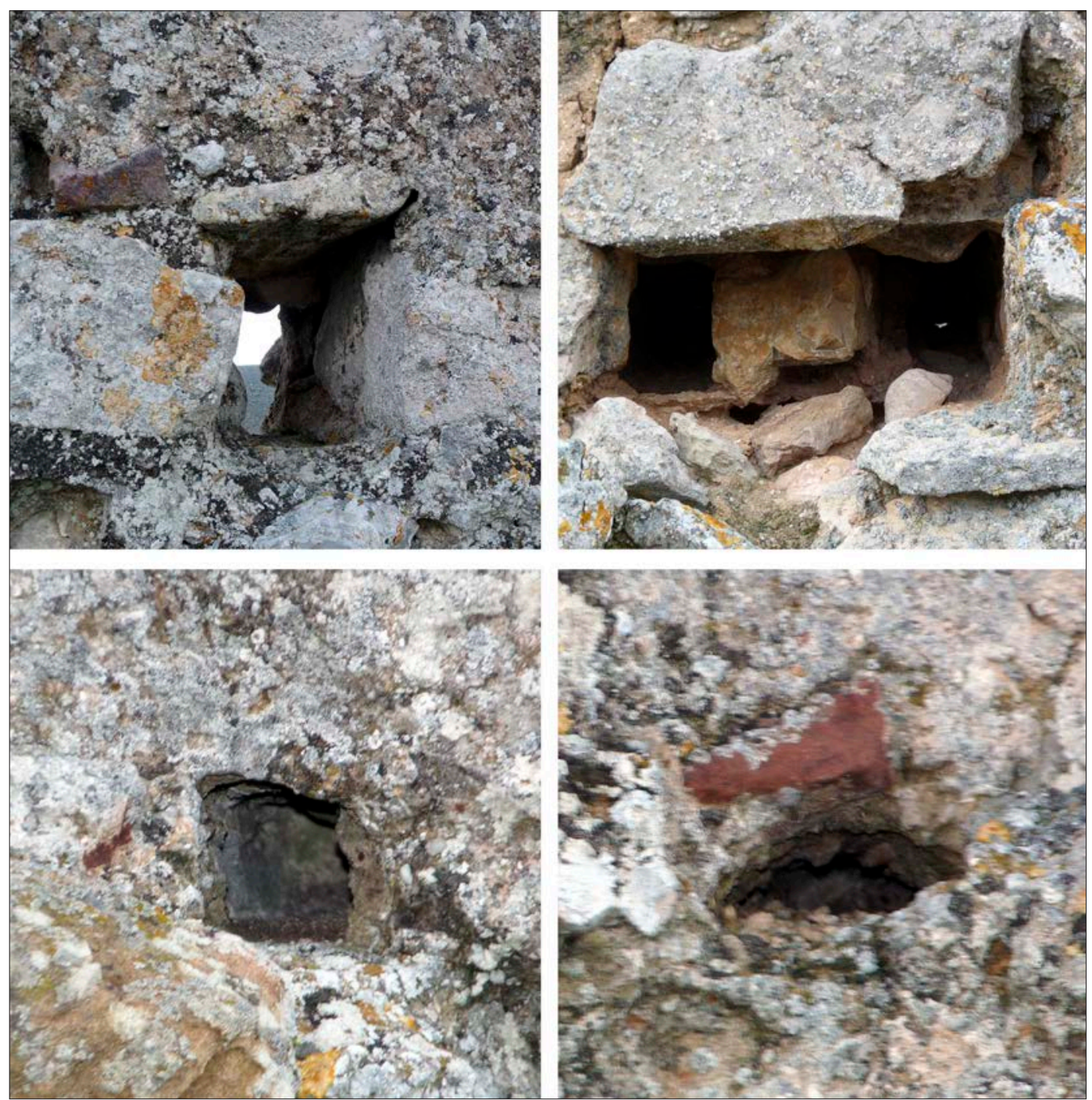

Figura 8. Mechinales del muro M3. a. Mechinal rectangular y pasante del tramo septentrional. $\boldsymbol{b}$. Mechinales rectangulares pareados correspondientes a una junta constructiva. c. Mechinal de sección cuadrangular en el tramo medio. $\boldsymbol{d}$. Mechinal correspondiente a una media aguja formada por un rollizo fajado en el tramo meridional.
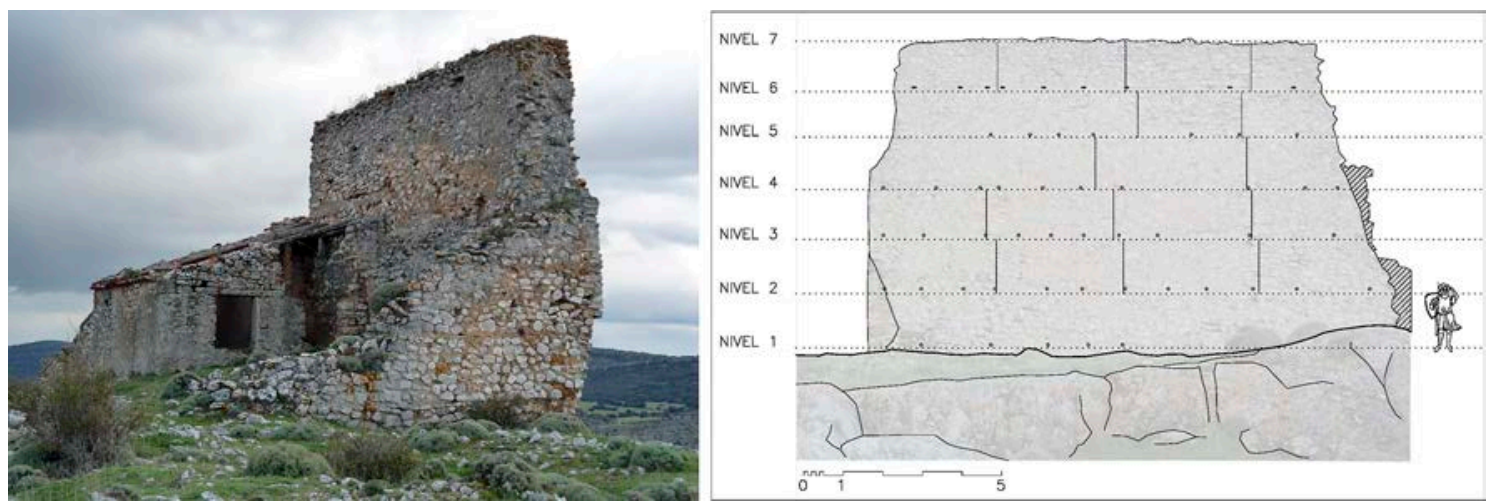

Figura 9. $\boldsymbol{a}$. Los restos TI desde el noreste, donde se aprecia el arranque del muro perpendicular a la muralla y la reducción del grosor del muro a partir del quinto nivel. $\boldsymbol{b}$. Alzado extramuros del muro occidental de los restos $T 1$ de las murallas de Peñalcázar, con indicación de los niveles constructivos y las juntas entre los sucesivos cajones de tapia de cal y canto, así como de los agujales visibles. 
limpios sin ninguna señal de traba con ningún muro que pudiera acometer contra ella.

De esta posible torre vigía, datada tradicionalmente como musulmana, de planta posiblemente rectangular sólo se conserva el muro occidental, de unos 12,5 m de longitud, y el arranque del orientado al norte. El muro orientado al oeste ha sido reaprovechado para un lagar. La torre está situada en el extremo orientado al valle del río Peñalcázar que une esta población con la de Almazul, y con un gran campo visual.

La fábrica conservada consta de siete hilos constructivos en los que han quedado marcadas las improntas de los cajones con junta vertical. Éstos alcanzan aproximadamente los $115-125 \mathrm{~cm}$ de altura, siendo la longitud total del muro de $11,60 \mathrm{~m}$ y su espesor de $210 \mathrm{~cm}$, aunque se reduce con la altura a partir del cuarto nivel. Las dimensiones de los cajones varían entre 320 y $350 \mathrm{~cm}$, habiendo algunos de $280 \mathrm{~cm}$. Por mor del solape -muy cercano éste- de las juntas verticales entre los sucesivos hilos constructivos se puede inferir que la construcción procedió en el mismo sentido que el muro M2, esto es: de norte a sur.

En el último nivel constructivo del muro, los mechinales son circulares y pareados, lo que es indicativo del empleo de varillas como agujas. No hay cambio de grosor ni de material y dimensionalmente es similar a la fábrica inferior; la única diferencia apreciable es el cambio en el sistema de agujas del encofrado. Este nivel se levanta sobre el último que corresponde al muro M2, por lo que pudo ser un recrecido.

La utilización de este tipo de agujas es visible en algunas torres-refugio del Campo de Gómara y la Tierra de Ágreda, en el cercano castillo de Peroniel del Campo y en las fortificaciones fronterizas entre León y Castilla levantadas durante la temporal separación de los reinos entre 1157 y 1230 (COBOS GUERRA, CASTRO FERNÁNDEZ Y CANAL ARRIBAS, 2012: pp. 109-112). Así como estas últimas están perfectamente datadas en un corto y concreto ámbito temporal y pueden servir de parámetro de control para un estudio cronotipológico -por lo que se podría datar tanto este último nivel constructivo de la torre T1 y el castillo de Peroniel como fábricas de mediados del siglo XII y principios del XIII-, en el caso de las torresrefugio se presentan algunas dudas sobre su construcción. Algunos autores (DOMÍNGUEZ HERNÁNDEZ, 1984; 1984-1985; LORENZO CELORRIO, 1994; 2003) adelantan su construcción a mediados del siglo X como una promoción califal para vigilar y controlar el territorio ante el avance castellano. Sin embargo, en otras investigaciones más recientes como las de Bernad Remón et alii (1997), Cobos Guerra y Castro Fernández (1998) o Cobos Guerra y Retuerce Velasco (2011) se entienden como torres de presura o de temprana repoblación, por lo que su construcción se puede retrasar hasta el siglo XII cuando se reconquista definitivamente y se organiza jurisdiccionalmente -a través de fueros que instituyen el sistema concejil municipal- el oriente soriano.

El análisis mensiológico no arroja ningún resultado concluyente que colabore a verificar la hipótesis de que esta fábrica data del siglo XII y es, por tanto, una obra de factura cristiana, ya que no hay una modulación evidente en las fábricas de las fortificaciones cristianas. En las torres-refugio las alturas de los tapiales rondan los 100-110 cm de altura. En el caso de Peñalcázar, este aspecto constructivo llega a alcanzar unas dimensiones mayores, si bien se mueve en el entorno de los 90-110-125 cm, lo que podría corresponder, en algunos casos, a dos codos de $55 \mathrm{~cm}$. En la fortificación de la frontera con León, la altura de los tapiales no guarda ninguna constancia, ya que se mueve en un rango muy amplio que llega a superar los $140 \mathrm{~cm}$ en algunos casos (MAÑNANES, VALBUENA Y ALONSO, 1980; COBOS GUERA, CASTRO FERNÁNDEZ Y CANAL ARRIBAS, 2012).

\section{CONCLUSIONES}

A pesar de la importancia relativa que este significativo enclave fortificado desarrolló durante los últimos años del califato, su primera reconquista por el Cid, sus asedios, tomas y devoluciones durante la Guerra de los Dos 
Pedros en el siglo XIV y durante la guerra con Navarra durante el XV, además de otros episodios modernos como la guerra de Sucesión en el XVIII, este análisis es el primer estudio monográfico de tan destacada fortificación.

La primera conclusión a la que se llega tras la observación atenta de los abultamientos visibles en la gran explanada vacía al sureste del núcleo de población y su cotejo con las ortofotografías y puesta en relación con la trama urbana es que tales abultamientos parecen pertenecer a estructuras antrópicas ocultas que bien pudieran ser los restos de la antigua fortaleza hispanomusulmana que siempre citan las crónicas como fuerte y grande y que los restos conservados no parecen cumplir con esos adjetivos.

Por lo tanto, los restos conservados son parte de las murallas y la torre donde algunos autores han interpretado que se situaba la fortaleza islámica no parece corresponder más que con una torre de flanqueo o un tramo de muralla. El estudio de las fábricas de las cortinas conservadas las pone en relación tanto con las torres-refugio de presura del campo de Gómara y la Sierra del Madero, el castillo de Peroniel del Campo y las fortificaciones fronterizas entre León y Castilla de los siglos XII y XIII.

Las diferencias constructivas entre las distintas fábricas de las murallas revelan distintas fases en su construcción y su mantenimiento como plaza fuerte a lo largo de la Edad Media, como se puede advertir tras su estudio documental.

La fortaleza de Peñalcázar es una construcción representativa de las soluciones constructivas bajomedievales y, en concreto, de la tapia de cal y canto o mampostería encofrada. El empleo de la tapia de cal y canto tuvo su apogeo en torno a los siglos XII y XIII, si bien hay casos posteriores. Esta fortaleza tiene un claro origen hispanomusulmán como acreditan las referencias históricas (ZAMORA LUCAS, 1961). Los restos de esta primera fortificación islámica no se han conservado a excepción de la torre T1, según Lorenzo Celorrio (2003: p. 165).
Sin embargo, al analizar constructivamente los restos conservados de las murallas de Peñalcázar se observa que no hay diferencias significativas entre los parámetros constructivos de la fábrica de la torre T1 y del muro M2, el cual continúa el mismo trazado. El proceso constructivo de ambas fábricas, según se desprende del solape de las juntas verticales entre los cajones de los sucesivos niveles constructivos, es el mismo: la construcción se inicia desde el norte y prosigue hacia el sur.

En el sexto nivel de la torre T1 se cambia el sistema de agujas, pues en lugar de agujas planas o cuadrangulares o de sección de sector de circunferencia se emplean varillas pareadas. Cabe la posibilidad de un cambio de operarios al llegar a ese nivel para elevar la altura de la torre sobre el nivel del adarve de la muralla. No obstante, no hay una diferencia sensible ni en el material ni en las dimensiones de los tapiales ni en el grosor del muro; tan sólo varía el sistema de agujas, por lo que pertenecen a la misma etapa constructiva.

Las hipótesis planteadas a partir del estudio de las estructuras murarias aparentes en las murallas de Peñalcázar sólo podrán ser verificadas mediante el análisis de caracterización y datación por medios físico-químicos, que urge realizar, de los restos lignarios conservados embebidos en los muros, además de una prospección arqueológica que permita descubrir las estructuras ocultas y rescatar objetos numismáticos, cerámicos o de cualquier tipo que colaboren en la verificación de la datación propuesta mediante las herramientas cronotipológicas y mensiológicas.

\section{BIBLIOGRAFÍA}

ACIÉN ALMANSA, Manuel (2008): «Poblamiento y sociedad en al-Andalus: un mundo de ciudades, alquerías y husun». En Cristiandad e Islam en la Edad Media hispana, editado por José Ignacio de la IGLESIA DUARTE. Logroño, Instituto de Estudios Riojanos.

BERNAD REMÓN, Javier; Inocencio CADIÑANOS; Fernando COBOS GUERRA; José Avelino GUTIÉRREZ; Jaime PINILLA (1997): «Castillos de Castilla y León. Provincia de Soria», Castillos de España, editado por BERNAD REMON, Javier (coord.). León, Everest. 
BLASCO JIMÉNEZ, Manuel (1909): Nomenclátor histórico, geográfico, estadístico y descriptivo de la provincia de Soria. Soria, Tipografía de Pascual P. Rioja.

CARRIÓN MATAMOROS, Eduardo (1998): «La zona oriental soriana en la Alta Edad Media: estructuras de población y sistema de defensas», Celtiberia. 92. 55-124.

COBOS GUERRA, Fernando; José Javier de CASTRO FERNÁNDEZ (1998): Castilla y León. Castillos y fortalezas. León, Edilesa.

COBOS GUERRA, Fernando; José Javier de CASTRO FERNÁNDEZ; Rodrigo CANAL ARRIBAS (2012): Castros y recintos de la frontera de León en los siglos XII y XIII. Fortificaciones de tapial de cal y canto o mampostería encofrada. Valladolid, Junta de Castilla y León. Consejería de Cultura y Turismo.

COBOS GUERRA, Fernando; Manuel RETUERCE VELASCO (2011): Metodología, valoración y criterios de intervención en la arquitectura fortificada de Castilla y León. Catálogo de las provincias de León, Salamanca, Valladolid y Zamora. Valladolid, Junta de Castilla y León.

CODERA Y ZAIDÍN, Francisco (1887): «Embajadores de Castilla encarcelados en Córdoba en los últimos años de Alhaquem Il». Boletín de la Real Academia de Historia. 14 (3). 187-193.

CODERA Y ZAIDÍN, Francisco (1917): Estudios críticos de Historia árabe española. Madrid, Imprenta Ibérica, E. Maestre.

DIAGO HERNANDO, Máximo (1987): «Expansión señorial en la tierra de Soria en la época Trastámara», Celtiberia 74. 201-238.

DIAGO HERNANDO, Máximo (1988): «Introducción a la historia institucional del concejo de Soria en la Baja Edad Media», En la España Medieval. 11. 23-43.

DIAGO HERNANDO, Máximo (1991): «El alcaide Juan de Luna: un hombre al servicio del condestable don Álvaro en la región soriana», Celtiberia. 81-82. 59-85.

DIAGO HERNANDO, Máximo (1992): Alfonso VIII y el Concejo de Soria. En I/ Curso de cultura medieval. Seminario Alfonso VIII y su época. Aguilar del Campoo 1-6 de octubre de 1990, editado por Jaime NUÑO GONZÁLEZ. Aguilar del Campoo, Centro de Estudios del Románico.

DIAGO HERNANDO, Máximo (2005): «Vicisitudes de un gran estado señorial en la frontera de Castilla con Aragón durante la primera mitad del siglo XIV: los señoríos sorianos del Infante Don Pedro», Anuario de Estudios Medievales, 35/1. 47-90.

DOMÍNGUEZ HERNÁNDEZ, Luis Pedro (1984): «Aportación al estudio de las torres y atalayas de la provincia de Soria en los siglos X y Xl», Artigrama. 1. 402-404.

DOMÍNGUEZ HERNÁNDEZ, Luis Pedro (1984-1985): «Tres torres-atalayas de la provincia de Soria: Castellanos, Masegoso y La Pica», Acta historica et archaeologica mediaevalia. 5-6. 257-280.

ESPINOSA DE LOS MONTEROS, Juan; Luis MARTÍN-ARTAJO SARACHO (1974): Corpus de los castillos medievales de Castilla. Bilbao, Clave.
GAYA NUNO, Juan Antonio (1932): «La torre árabe de Noviercas (Soria)», Archivo Español de Arte y Arqueología. 24. 219-232.

JIMÉNEZ ESTEBAN, Jorge (1997): El castillo medieval. Murcia, DM.

LÁZARO CARRASCOSA, Santiago (2007): «Aproximación al estudio del sistema defensivo musulmán en la frontera de la zona oriental soriana (siglos X-XII)», Revista de Soria. 56. 29-74.

LÓPEZ DE AYALA, Pedro (1779): Crónicas de los reyes de Castilla don Pedro, don Enrique II, don Juan I, don Enrique III. Tomo I que comprende la crónica del rey don Pedro. Vol. 1. Madrid, Imprenta de don Antonio de Sancha.

LORENZO CELORRIO, Ángel (1994): «Torres refugio en la cuenca del Rituerto (Soria). Una zona de frontera del califato cordobés». Actas del I congreso de Castellología Ibérica, editado por Áurea DE LA MORENA, Ivette HINEN DE TEROL, Amador RUIBAL, Jorge JIMÉNEZ ESTEBAN, Fermín DE LOS REYES y Rafael ARDANAZ. Palencia, Diputación Provincial de Palencia.

LORENZO CELORRIO, Ángel (2003): Compendio de los castillos medievales de la provincia de Soria en el que se incluyen torres y atalayas de la misma época. Aumentado con las trazas de los ejemplares más representativos y adornado con ilustraciones de aquéllos que conservan restos significativos. Soria, Diputación Provincial de Soria.

LOPERRÁEZ CORVALÁN, Juan (1788): Descripción histórica del Obispado de Osma. Madrid, Imprenta Real.

MADOZ, Pascual (1845-1850): Soria, Diccionario Geográfico-Estadístico-Histórico de Castilla y León. Valladolid, Ámbito, Diputación de Soria.

MALALANA UREÑA, Antonio (2009): «La evolución de los recintos urbanos amurallados castellano-leoneses a lo largo del siglo XII», Arqueología y territorio medieval. 16. $73-136$.

MANZANO MORENO, Eduardo (1989): La organización fronteriza en al-Andalus durante la época omeya: aspectos militares y sociales (756-976/138-366H). Madrid, Universidad Complutense de Madrid.

MANZANO MORENO, Eduardo (2006): Conquistadores, emires y califas. Los Omeyas y la formación de al-Andalus. Barcelona, Crítica.

MANZANO MORENO, Eduardo (2008): «La línea del Duero a la luz de las fuentes árabes». Biblioteca: estudio e investigación. 23. 65-74.

MAÑANES, Tomás; Felipe VALBUENA; José Luis ALONSO PONGA (1980): «La arquitectura militar en la frontera del reino de León con el de Castilla en los siglos XII y XIII (1)», Tierras de León: Revista de la Diputación Provincial. 20/40: 89-114.

MAÑANES, Tomás; Felipe VALBUENA; José Luis ALONSO PONGA (1980): «La arquitectura militar en la frontera del reino de León con el de Castilla en los siglos XII y XIII (2)», Tierras de León: Revista de la Diputación Provincial 20/41. 59-88 
MARTÍNEZ ALONSO, Juan Vicente (2012): «El fuero de Alfonso X otorgado a la villa de Serón en el año 1263 y otros sucesos históricos medievales», Celtiberia. 106. 93-132.

MASIÁ DE ROS, Ángeles (1994): Relación castellanoaragonesa desde Jaime II a Pedro el Ceremonioso. Barcelona, CSIC.

Miñano y Bedoya, Sebastián de (1826-1829). Diccionario Geográfico-Estadístico de Soria. Editado por Silvano Andrés de la Morena (2004). Soria, Soria Edita.

Monsalvo Antón, José María (2003): «Frontera pionera, monarquía en expansión y formación de los concejos de villa y tierra. Relaciones de poder en el realengo concejil entre el Duero y el Tajo (c. 1072-c.1222)», Arqueología y territorio medieval. 10/2. 45-126.

PÉREZ RIOJA, José Antonio (dir.) (1985): Historia de Soria. Soria, Centro de Estudios Sorianos.

QUINTANILLA RASO, María Concepción (1986): «La tenencia de fortalezas en Castilla durante la Baja Edad Media», En la España Medieval. 5. 861-895.
RABAL, Nicolás (1889): Soria. Barcelona, Establecimiento tipográfico-editorial de Daniel Cortezo y C.

RETUERCE VELASCO, Manuel; COBOS GUERRA, Fernando (2002): «Fortificación islámica en el Alto Duero versus fortificación cristiana en el Alto Duero». En Cuando las horas primeras. En el milenario de la Batalla de Calatañazor. Soria, Universidad Internacional Alfonso VIII.

SARR, Bilal (2013): «Introducción al estudio del poblamiento beréber en la marca superior de al-Andalus (siglos VIII-XII)». Melanges de la Casa de Velazquez. 43 (1). 209-230.

SERRANO-PIEDECASAS FERNÁNDEZ, Luis (2007): «Sistemas islámicos de dominio en los Extrema Durii». En Espacios de poder y formas sociales en la Edad Media, editado por Gregorio del SER QUIJANO e Iñaki MARTÍN VISO. Salamanca, Universidad de Salamanca.

ZAMORA LUCAS, Florentino (1961): «Batallas de Deza y de Almenar en el año 974», Celtiberia. 22. 259-265. 